\title{
Title: Paediatric Intentional Head Injuries in the Emergency Department. A multicentre prospective cohort study
}

Franz E Babl MD ${ }^{\mathrm{a}, \mathrm{b}, \mathrm{c}}$, Helena Pfeiffer ${ }^{\mathrm{a}, \mathrm{b}}$, Stuart R Dalziel PhD ${ }^{\mathrm{d}, \mathrm{e}}$, Ed Oakley MBBS ${ }^{\mathrm{a}, \mathrm{b}, \mathrm{c}}$, Vicky Anderson PhD ${ }^{\mathrm{a}, \mathrm{b}, \mathrm{c}}$, Meredith L Borland MBBS ${ }^{\mathrm{f}, \mathrm{g}}$, Natalie Phillips MBBS ${ }^{\mathrm{h}}$, Amit Kochar MD ${ }^{\mathrm{i}}$,

Sarah Dalton BMed ${ }^{\mathrm{j}}$, John A. Cheek MBBS ${ }^{\mathrm{a}, \mathrm{b}, \mathrm{k}}$, Yuri Gilhotra MBBS ${ }^{\mathrm{h}}$, Jeremy Furyk MBBS $^{1}$, Jocelyn Neutze MBChB ${ }^{\mathrm{m}}$, Mark D. Lyttle $\mathrm{MBChB}^{\mathrm{b}, \mathrm{n}, \mathrm{o}}$, Silvia Bressan MD, $\mathrm{PhD}^{\mathrm{b}, \mathrm{p}}$, Susan Donath MA ${ }^{\mathrm{b}, \mathrm{c}}$, Stephen J.C. Hearps PGDipBiostat ${ }^{\mathrm{b}}$, Louise Crowe ${ }^{\mathrm{b}} \mathrm{PhD}$ on behalf of the Paediatric Research in Emergency Departments International Collaborative (PREDICT)

\author{
Affiliations: \\ ${ }^{a}$ Royal Children's Hospital, Melbourne, Australia; \\ 'Murdoch Children's Research Institute, Melbourne, Australia; \\ ${ }^{c}$ Department of Paediatrics, Faculty of Medicine, Dentistry and Health Sciences, University \\ of Melbourne, Melbourne, Australia; \\ 'Starship Children's Health, Auckland, New Zealand; \\ 'Liggins Institute, University of Auckland, Auckland, New Zealand; \\ ${ }^{f}$ Princess Margaret Hospital for Children, Perth, Australia; \\ ${ }^{\mathrm{g}}$ Divisions of Paediatrics and Emergency Medicine, School of Medicine, University of \\ Western Australia, Crawley, Australia; \\ h'Lady Cilento Children's Hospital, Brisbane and Child Health Research Centre, School of \\ Medicine, The University of Queensland, Brisbane, Australia; \\ 'Women's \& Children's Hospital, Adelaide, Australia; \\ j'The Children's Hospital at Westmead, Sydney, Australia; \\ ${ }^{k}$ Monash Medical Centre, Melbourne, Australia; \\ ${ }^{1}$ The Townsville Hospital, Townsville, Australia; \\ ${ }^{\mathrm{m}}$ Kidzfirst Middlemore Hospital, Auckland, New Zealand; \\ ${ }^{\mathrm{n}}$ Bristol Royal Hospital for Children, Bristol, United Kingdom; \\ ${ }^{\circ}$ Academic Department of Emergency Care, University of the West of England, Bristol, \\ United Kingdom; \\ ${ }^{\mathrm{p}}$ Department of Women's and Children's Health, University of Padova, Padova, Italy
}

\section{Contributors' Statement}

Franz E Babl: Conceived the study, obtained grant funding, designed the study, provided overall supervision, interpreted the data, gave final approval to be published, and agreed to be accountable for all aspects of the work.

Helena Pfeiffer: Identified the patients for this secondary analysis, wrote the initial draft und revised the article

This is the author manuscript accepted for publication and has undergone full peer review but has not been through the copyediting, typesetting, pagination and proofreading process, which may lead to differences between this version and the Version of Record. Please cite this article as doi: $10.1111 / 1742-6723.13202$ 
Stuart R Dalziel, Ed Oakley, Vicky Anderson, Meredith Borland, Natalie Phillips, Amit Kochar, Sarah Dalton, John A. Cheek, Yuri Gilhotra, Jeremy Furyk, Jocelyn Neutze, Mark D Lyttle, Silvia Bressan, Louise Crowe: Designed the study, obtained the data, provided supervision, interpreted the data and drafted or revised it critically

Susan Donath, Stephen Hearps: Designed the study, analysed the data, contributed to the interpretation of the data and revised the paper critically

Short title: Paediatric intentional head injuries in the ED

Address correspondence to: Franz E Babl, MD MPH, Emergency Research, Murdoch Children's Research Institute, 50 Flemington Road, Parkville, Victoria, 3052, Australia, Ph: +613-9345 6592, Fax: +613-9345 5938, franz.babl@mcri.edu.au

Word Count: 2452 


\begin{abstract}
(250)
Objective: While there is a large body of research on head injury (HI) inflicted by caregivers in young children, little is known about intentional HI in older children, and inflicted HI by perpetrators other than carers. Therefore we set out to describe epidemiology, demographics and severity of intentional HIs in childhood.
\end{abstract}

Methods: Planned secondary analysis of a prospective multicentre cohort study conducted in ten emergency departments in Australia and New Zealand including children aged $<18$ years with HIs. Epidemiology codes were used to prospectively code the injuries. Demographic and clinical information including the rate of clinically important traumatic brain injury (ciTBI: HI leading to death, neurosurgery, intubation $>1 \mathrm{~d}$ or admission e $2 \mathrm{~d}$ with abnormal CT) was descriptively analysed.

\title{
Results:
}

Intentional injuries were identified in 372 of 20,137 (1.8\%) head injured children. Injuries were caused by caregivers $(103,27.7 \%)$, by peers $(97,26.1 \%)$, by siblings $(47,12.6 \%)$, by stranger $(35,9.4 \%)$, by persons with unknown relation to patient $(21,5.6 \%)$, other intentional injuries $(8,2.2 \%)$, or undetermined intent $(61,16.4 \%) .75 .7 \%$ of victims of assault by caregiver were $<2$ years, whereas in other categories only $4.9 \%$ were $<2$ years. Overall, $66.9 \%$ of victims were male. Rates of CT performance and abnormal CT varied: assault by caregivers $68.9 \% / 47.6 \%$, by peers $18.6 \% / 27.8 \%$, by strangers $37.1 \% / 5.7 \%$. ciTBI rate was $22.3 \%$ in assault by caregivers, $3.1 \%$ when caused by peers and $0.0 \%$ with other perpetrators.

\section{Conclusions:}

Intentional HI is infrequent in children. The most frequently identified perpetrators are caregivers and peers. Caregiver injuries are particularly severe.

Keywords: Bullying, Child Abuse, Craniocerebral Trauma, Paediatric Emergency Medicine, Violence 


\section{INTRODUCTION}

Intentional traumatic injuries in children are associated with higher mortality compared to accidental paediatric trauma. ${ }^{1}$ Abusive head trauma (AHT) or head injuries (HI) inflicted by caregivers, is the leading cause of traumatic death in the first year of life, and the most common cause of death due to child abuse. ${ }^{2}$ Only $22 \%$ of victims of AHT survive without any impairment of social, cognitive or motor abilities. ${ }^{3}$ However, as research has to date focussed on head injuries due to assault by caregivers or $\mathrm{AHT}^{4}$, there is limited understanding of intentional head injuries in general.

In studies of paediatric trauma patients in the United Kingdom, Israel, Malawi and Australia, intentional injuries made up $3.1-10.5 . \%{ }^{1,5-7}$ of all injuries. Emergency Department (ED) reports of HIs describe variable but low rates of intentional causation; however, these are often hampered by their single centre and retrospective methodology ${ }^{8-13}$. Reports from the US show high levels of intentional HIs, many in adolescents, and many caused by weapons ${ }^{12}$. Specific information on perpetrators and circumstances surrounding intentional HIs outside AHT is very limited.

We set out to investigate in a prospective multi-centre study the characteristics of intentional HIs in children presenting to the EDs of 10 hospitals in Australia and New Zealand, focussing on epidemiology, demographics and severity of intentional head injuries.

\section{METHODS}

This article is protected by copyright. All rights reserved. 


\section{Study design, setting and patients}

We performed a planned secondary analysis of children with intentional HIs enrolled into a prospective multi-centre observational study performed in 10 paediatric EDs in Australia and New Zealand between April 2011 and November 2014. All EDs are members of the Paediatric Research in Emergency Departments International Collaborative (PREDICT) research network. ${ }^{14}$

In the primary study we aimed to externally validate clinical decision rules (CDRs) for neuroimaging in mild traumatic brain injury (TBI); as such we collected and analysed CDRspecific predictor and outcome variables in all children aged $<18$ years presenting with $\mathrm{HI}{ }^{15}$,

${ }^{16}$ The parent study enrolled patients with HIs of any severity, but excluded the following: trivial facial injury only, patient/ family refusal to participate, referral from ED triage to an external provider (i.e. not seen in the ED), did not wait to be seen, or neuroimaging done prior to the transfer to a study site.

The study was approved by the institutional ethics committee at each participating site. We obtained informed verbal consent from parents/guardians. However, in instances of significant life-threatening or fatal injuries, ethics committees granted a waiver of consent. The study was registered with the Australian New Zealand Clinical Trials Registry (ANZCTR) ACTRN12614000463673.

\section{Study procedures}

The study protocol is described in detail elsewhere. ${ }^{16}$ Children were enrolled by the treating ED clinician who collected data points for the HI CDRs. A research assistant (RA) recorded ED and hospital management data after the visit and conducted a telephone follow-up for 
patients who had not undergone neuroimaging. In addition to data related to CDRs we collected demographic and epidemiological information about neuroimaging, admission and neurosurgery.

To identify the intentional injuries among our population, we searched the study database for all cases with a human intent code other than non-intentional codes. These codes are part of routinely collected epidemiology codes in several Australasian jurisdictions; standardised epidemiology codes based on Victorian state codes (19) were incorporated into the clinical report forms (CRF) across all study sites. In addition, the CRFs included the question "Do you suspect non-accidental injury (Physical abuse of a child, not other assault)?" as this was a feature in some of the CDR derivation studies we investigated in the parent study. We reviewed the 309 cases where the clinicians ticked "yes" or "unknown". CRFs and radiology reports of all identified cases were manually reviewed.

For this analysis we excluded cases coded as intentional injury caused by peer where the activity code related to sports, as the historical determination of accidental versus intentional $\mathrm{HI}$ is difficult in game play.

\section{Definitions}

We used the Glasgow Coma Scale (GCS) as initially assigned by the ED clinician in the analysis, or if not available, GCS at triage. ${ }^{17}$

Senior radiologist reports were used to determine the results of computerised tomography (CT) scans and operative reports for patients who underwent neurosurgery.

Abnormal CT was defined as intracranial haemorrhage or contusion, cerebral oedema, traumatic infarction, diffuse axonal injury, shearing injury, sigmoid sinus thrombosis, midline 
shift of intracranial contents or signs of brain herniation, diastasis of the skull, pneumocephalus ${ }^{18}$ or any skull fracture (depressed, non-depressed, basal, unknown type). Clinically-important TBI (ciTBI) was defined as death, neurosurgical intervention, intubation $>24$ hours for TBI, or hospital admission of two nights or more for traumatic HI associated with abnormality on CT. ${ }^{18}$

Neurosurgical intervention was defined as intracranial pressure monitoring, elevation of depressed skull fracture, ventriculostomy, haematoma evacuation, lobectomy, tissue debridement or dura repair.

The categorisation of intentional injuries was based on the judgment of the treating ED clinician or subsequent hospital clinician based on information collected in the CRFs. These included information from the ED visit and medical records, but records were only accessed by site RAs immediately after the visit; subsequent assessments in case conferences or as assessed by external agencies (police, courts) were in general not available at the time of RA data extraction to determine whether the presumed diagnosis or initial assessment was confirmed. For ease of description in abstract and manuscript we use the term "caused by x" instead of "presumed assault by x".

\section{Epidemiology codes}

We used epidemiology codes based on Victorian government codes ${ }^{19}$ that included activity, place, mechanism of injury and human intent. Codes were assigned by trained RAs at each site based on information recorded by the clinician at the time of the ED visit, and by RAs during the follow-up call. Table 1 shows the human intent codes used. We combined the 
small number of cases of intentional head injuries due to self-harm, legal intervention and other causes into a category of "other intentional injuries" to avoid case identification.

\section{Insert Table 1}

\section{Statistical analysis}

Data were entered into Epidata (The Epidata Association, Odense, Denmark), and later REDCap, ${ }^{24}$ and analysed using Stata 13 (Statacorp, College Station, Texas, USA).

\section{RESULTS}

Of the 20,137 head injured children recruited, we identified 372 children (1.8\%) who had suffered intentional injuries, based on clinician suspicion or RA assigned epicodes (Figure 1). Injuries caused by caregiver $(103,27.7 \%)$ was most common, followed by injuries caused by peers $(97,26.1 \%)$, siblings $(47,12.6 \%)$, street attacks by strangers $(35,9.4 \%)$, attacks by person with unknown relation to patient $(21,5.6 \%)$, and other intentional injuries $(8,2.3 \%)$. In 61 cases (16.4\%) human intent could not be determined (Figure 1). Overall, 66.9\% of victims were male and in every category of intentional injuries male victims predominated with largest male dominance in adolescent peer injuries and street attacks (Table 2).

\section{Insert Figure 1 and Table 2}

In children $<2$ years caregiver assault accounted for $89.7 \%$ of intentional HIs. In the age group of 2 to 10 years, intentional injuries were mainly caused by peers $(47.1 \%)$ and siblings $(29.4 \%)$ and less by caregivers (20.0\%). In children aged 11 to 18 years injuries were predominantly peer assaults $(41.0 \%)$, and attacks by strangers $(25.2 \%)$. Children $<2$ years old accounted for $75.7 \%$ (78 out of 103 ) of cases of caregiver assault, and only $4.9 \%$ (9 of 208) 
of cases of assault by other perpetrators (Figure 2 and Table 2). None of the HIs were caused by gunshot wounds.

\section{Insert Figure 2}

Where the place of injury was specified, the places where the highest number of intentional injuries occurred were school grounds and home living area (Figure 3).

\section{Insert Figure 3}

Victims of assault by caregivers underwent CT in $68.9 \%$ ( 71 out of 103 ) of cases and $69.0 \%$ (49 of 71) were abnormal. The most common injuries were skull fractures $(69.4 \%$ of abnormal CT scans) and intra-cranial haemorrhage/contusion (61.2\%). Of children and adolescents attacked by strangers $37.1 \%$ (13 of 35) had a CT scan, with $15.4 \%$ of these scans abnormal. Out of 97 peer injured children, only 18 (18.6\%) underwent CT and in $27.8 \%$ of these, abnormalities were detected. Only 1 out of 47 children injured by their siblings had a CT scan (Table 3 and Figure 4).

\section{Insert Table 3 and Figure 4}

Major signs and symptoms are shown in Table 2. A high rate of known or suspected loss of consciousness was found in attacks by strangers (51.4\%) and attacks by persons with unknown relation to patient (42.9\%).

This article is protected by copyright. All rights reserved. 
Admission rates varied from $77.7 \%$ for injuries caused by caregivers, $37.1 \%$ attack by stranger, $23.7 \%$ by peer and $8.5 \%$ by sibling. Twenty-two per cent of injuries by caregivers were categorized as ciTBI. Three cases $(3.0 \%)$ of injury by peers were the only other cases with an injury meeting our ciTBI definition. There were two fatalities $(1.9 \%)$, both from injury by caregivers (Table 2).

Peer assault occurred mainly on school days (93.8\%), assault by strangers peaked on weekends, especially on Saturday (28.1\%), while caregivers assaults presented evenly across the days of the week. In terms of reported time of injury, peer injuries peaked between 10 AM and 3 PM, whereas most sibling injuries occurred after school between 4 PM and 9 PM. (Figure 5). In assaults by caregivers the timing of the injury was missing in $27.2 \%$.

\section{Insert Figure 5}

\section{DISCUSSION}

In this large multicentre prospective data set we have provided detailed information about intentional HIs in children and adolescents presenting to EDs. In this population intentional HIs were infrequent, accounting for only $1.8 \%$ of all HIs presenting to major EDs in Australia and New Zealand. Adolescents aged 11-18 years were most likely to sustain intentional HI overall. The most common perpetrators were caregivers in young children and peers in adolescent patients. The rate of intentional injuries in this study was similar to the $3.3 \%$ reported in an earlier retrospective review of head-injured children presenting to one of the tertiary referral centres included in this study in $2004 .^{8}$ 
Although CT imaging was completed based on the concern of individual clinicians for intracranial injury and in assaults by caregivers may also have been driven by local protocols or practices for the work up these patients, detected abnormalities and the uneven distribution of ciTBIs and fatalities show that the severity of injuries are associated with the perpetrator and the age of the child victim. Assaults by caregivers were associated with more severe injuries, whereas injuries inflicted by peers and siblings were less likely to involve detectable cranial or intracranial abnormalities. This is broadly in keeping with several studies reporting higher severity of TBI associated with caregiver assaults compared with accidental injuries ${ }^{20}$ and research showing that paediatric trauma caused by child abuse is more severe than trauma from other causes. ${ }^{1}$

Assaults by strangers or persons with unknown relation to patient, were associated with a higher rate of CT scanning compared with attacks by peers or siblings $(20 / 56(35.7 \%) \mathrm{vs}$. $19 / 144(13.2 \%))$. Yet the rate of abnormal neuroimaging was about the same in these groups $(3 / 56(5.4 \%)$ vs. $6 / 144(4.2 \%))$ and symptoms were similar between the two groups. The reasons for the higher rate of $\mathrm{CT}$ scanning are unclear. However those attacked by a stranger or a person with unknown relationship were older and less likely to have a fall as mechanism of their HI-

There were very obvious relationships between age at injury and type of intentional injuries. The median age for suspected assault by caregiver was 0.8 years, by peer 13 years and by 
stranger 15 years, while the median age for non-accidental trauma overall was 4 years. This is consistent with studies of paediatric trauma, which have reported that caregiver abuse almost exclusively occurs during the first years of life whereas peer and stranger assault is more common in teenagers. ${ }^{1,5}$

\begin{abstract}
Almost all intentional peer injuries happened during weekdays at school. In some cases bullying was explicitly mentioned in the clinical report form, yet this information was not systematically elicited. In the clinical setting, it is important to consider and ask about this issue, as bullying victimization may also be associated with a high level of psychosomatic or psychosocial health problems. ${ }^{21}$ Most incidents occurred during lunchtime. Locations of assaults by strangers included street, railway station and park and most frequently happened during the weekend.
\end{abstract}

Assaults by caregivers were characterised by a high rate of unknown place and time $(27.2 \%)$ recordings. This is consistent with a missing, vague, variable or possibly false history provided by caregivers, and an inability to gain this information accurately from young children and infants. This is also in keeping with Hettler and Greenes' finding, that no history of trauma had a high specificity for the detection of injuries inflicted by caregivers. ${ }^{22}$ In young patients with HI and unclear history of trauma, clinical prediction rules for AHT may assist clinicians in deciding which patients to evaluate for abuse. ${ }^{23,24}$ 
A striking finding in our dataset is the complete lack of gunshot wounds among the over 20,000 children enrolled in APHIRST.

\section{Limitations}

This study has several limitations. It relies on epidemiology coding by trained site RAs, which is dependent on the accuracy and detail of the history recorded by nursing and medical staff during the ED and hospital stay. We included all cases in which assault by caregiver was considered and/or investigated, not cases in which abusive head trauma was confirmed. This methodology varies from many previous reports on child abuse that have included only cases of confirmed AHT. The finding that injuries are especially severe in children abused by caregivers could be influenced by an increased consideration of suspected abuse in severely injured children. It is also possible that patients with intentional HIs were not identified by clinicians as such and assumed to be non-intentional $\mathrm{HI}$ on the basis of a false history by the caregiver or the patients. Furthermore, a small number of caregiver assaults may have presented with $\mathrm{HI}$ in the care of child protection officers or care givers who may have declined consent, or were unable to give consent to participate in the study. In addition, children assaulted by caregivers may also have been admitted with initial medical diagnosis and diagnosed as intentional injuries later in the hospital course. Our study would not have identified these children as our entry point was the ED setting. While we included all assaults by siblings and peers, the perpetrators may have been relatively young; we were unable to determine at what perpetrator age these should be considered genuine safeguarding concerns. 


\section{Conclusions}

Intentional HIs are infrequent in children presenting to the ED in Australia and New Zealand. The most frequent causes are assault by caregivers and by peers. Suspected assaults by caregivers are associated with high rates of $\mathrm{CT}$ abnormalities, clinically important traumatic brain injury and mortality.

This article is protected by copyright. All rights reserved. 


\section{Acknowledgements:}

We would like to thank the participating families and emergency department staff at participating sites. We would like to thank research staff from participating sites.

Funding Source: The study was funded by grants from the National Health and Medical Research Council (project grant GNT1046727, Centre of Research Excellence for Paediatric Emergency Medicine GNT1058560), Canberra, Australia; the Murdoch Childrens Research Institute, Melbourne, Australia; the Emergency Medicine Foundation (EMPJ-11162), Brisbane, Australia; Perpetual Philanthropic Services (2012/1140), Australia; Auckland Medical Research Foundation (No. 3112011) and the A Board), Auckland, New Zealand; WA Health Targeted Research Funds 2013, Perth, Australia; the Townsville Hospital and Health Service Private Practice Research and Education Trust Fund, Townsville, Australia; and supported by the Victorian Government's Infrastructure Support Program, Melbourne, Australia. FEB's time was part funded by a grant from the Royal Children's Hospital Foundation, Melbourne, Australia, an NHMRC Practitioner Fellowship and a Melbourne Campus Clinician-Scientist-Fellowship. SRD's time was part funded by the Health Research Council of New Zealand (HRC13/556).

Financial Disclosure: The authors have no financial relationships relevant to this article to disclose.

Conflict of interests: None of the authors have conflicts of interests.

Abbreviations: abusive head trauma (AHT), clinical decision rule (CDR), clinically important traumatic brain injury (ciTBI), clinical report form (CRF), computed tomography (CT), Glasgow Coma Scale (GSC), emergency department (ED), head injury (HI),Paediatric Research in emergency Departments International Collaborative (PREDICT), research assistant (RA), traumatic brain injury (TBI), 


\section{REFERENCES}

[1] Davies FC, Coats TJ, Fisher R, Lawrence T, Lecky FE. A profile of suspected child abuse as a subgroup of major trauma patients. Emergency medicine journal : EMJ. 2015; 32: 921-5.

[2] Duhaime AC, Christian CW, Rorke LR, Zimmerman RA. Nonaccidental head trauma in infants the "Shaken baby syndrome". N Engl J Med 1999. 1999; 338: 1822-29. [3] Makaroff KL, Putnam FW. Outcomes of infants and children with inflicted traumatic brain injury. Dev Med Child Neurol. 2003; 45: 497-502.

[4] Xiang J, Shi J, Wheeler KK, Yeates KO, Taylor HG, Smith GA. Paediatric patients with abusive head trauma treated in US Emergency Departments, 2006-2009. Brain injury. 2013; 27: 1555-61.

[5] Deasy C, Gabbe B, Palmer C, et al. Paediatric and adolescent trauma care within an integrated trauma system. Injury. 2012; 43: 2006-11.

[6] Rozenfeld M, Peleg K. Violence-related injury of children in Israel: age-dependent pattern. Bull World Health Organ. 2009; 87: 362-8.

[7] Gallaher JR, Wildfire B, Mabedi C, Cairns BA, Charles AG. Intentional injury against children in Sub-Saharan Africa: A tertiary trauma centre experience. Injury. 2016; 47: 837-41.

[8] Crowe L, Babl F, Anderson V, Catroppa C. The epidemiology of paediatric head injuries: data from a referral centre in Victoria, Australia. J Paediatr Child Health. 2009;

45: 346-50.

[9] Hawley C, Wilson J, Hickson C, Mills S, Ekeocha S, Sakr M. Epidemiology of paediatric minor head injury: Comparison of injury characteristics with Indices of Multiple Deprivation. Injury. 2013; 44: 1855-61.

[10] Bayreuther J, Wagener S, Woodford M, Edwards A, Lecky F, Bouamra 0, ..., Dykes, E. Paediatric trauma: Injury pattern and mortality in the UK. Archives of Disease in Childhood. 2009; 94: 37-41.

[11] Falk A. Current incidence and management of children with traumatic head injuries: The Stockholm experience. Developmental Neurorehabilitation. 2007; 10: 4955.

[12] Durkin M, Olsen S, Barlow B, Virella A, Connolly E. The epidemiology of urban pediatric neurological trauma: evaluation of, and implications for, injury prevention programs. Neurosurgery. 1998; 42: 300-10.

[13] Bowman S, Bird T, Aitken M, Tilford J. Trends in hospitalizations associated with pediatric traumatic brain injuries. Pediatrics. 2008; 122: 988-93. 
[14] Babl F, Borland M, Ngo P, et al. Paediatric Research in Emergency Departments International Collaborative (PREDICT): first steps towards the development of an Australian and New Zealand research network. Emerg Med Australas. 2006; 18: 143-7. [15] Babl FE, Borland ML, Phillips N, et al. Accuracy of PECARN, CATCH, and CHALICE head injury decision rules in children: a prospective cohort study. Lancet. 2017.

[16] Babl FE, Lyttle MD, Bressan S, et al. A prospective observational study to assess the diagnostic accuracy of clinical decision rules for children presenting to emergency departments after head injuries (protocol): the Australasian Paediatric Head Injury Rules Study (APHIRST). BMC Pediatr. 2014; 14: 148.

[17] Teasdale G, Jennett B. Assessment of coma and impaired consciousness. A practical scale. Lancet. 1974; 2: 81-4.

[18] Kuppermann N, Holmes JF, Dayan PS, et al. Identification of children at very low risk of clinically-important brain injuries after head trauma: a prospective cohort study. Lancet. 2009; 374: 1160-70.

[19] Victorian Emergency Minimum Dataset (VEMD) User Manual. In: The Department of Health and Human Services (ed.). Victoria 2016.

[20] Sills MR, Libby AM, Orton HD. Prehospital and in-hospital mortality: a comparison of intentional and unintentional traumatic brain injuries in Colorado children. Arch Pediatr Adolesc Med. 2005; 159: 665-70.

[21] Fekkes M, Pijpers FI, Fredriks AM, Vogels T, Verloove-Vanhorick SP. Do bullied children get ill, or do ill children get bullied? A prospective cohort study on the relationship between bullying and health-related symptoms. Pediatrics. 2006; 117: 1568-74.

[22] Hettler J, Greenes DS. Can the initial history predict whether a child with a head injury has been abused? Pediatrics. 2003; 111: 602-7.

[23] Pfeiffer H, Crowe L, Kemp AM, et al. Clinical prediction rules for abusive head trauma: a systematic review. Archives of disease in childhood. 2018; 103: 776-83.

[24] Pfeiffer H, Smith A, Kemp AM, et al. External Validation of the PediBIRN Clinical Prediction Rule for Abusive Head Trauma. Pediatrics. 2018; 141. 
$\underline{\text { Table } 1 \text { - Human Intent Codes }}$

Adv. Effect/ Complication of Therapy

Assault by partner

Assault by stranger

Assault by person with unknown relation to patient

Child abuse (caused by caregiver)

Intent not specified

Intentional self-harm

Law enforcement intervention

Non intentional harm

Other assault

Other specified intent

Caused by peer

Caused by sibling

Sexual assault

Undetermined intent

This article is protected by copyright. All rights reserved. 
Table 2: Demographics, mechanism of injury, symptoms/signs, management and outcome of injuries comparing subgroups of intentional injuries

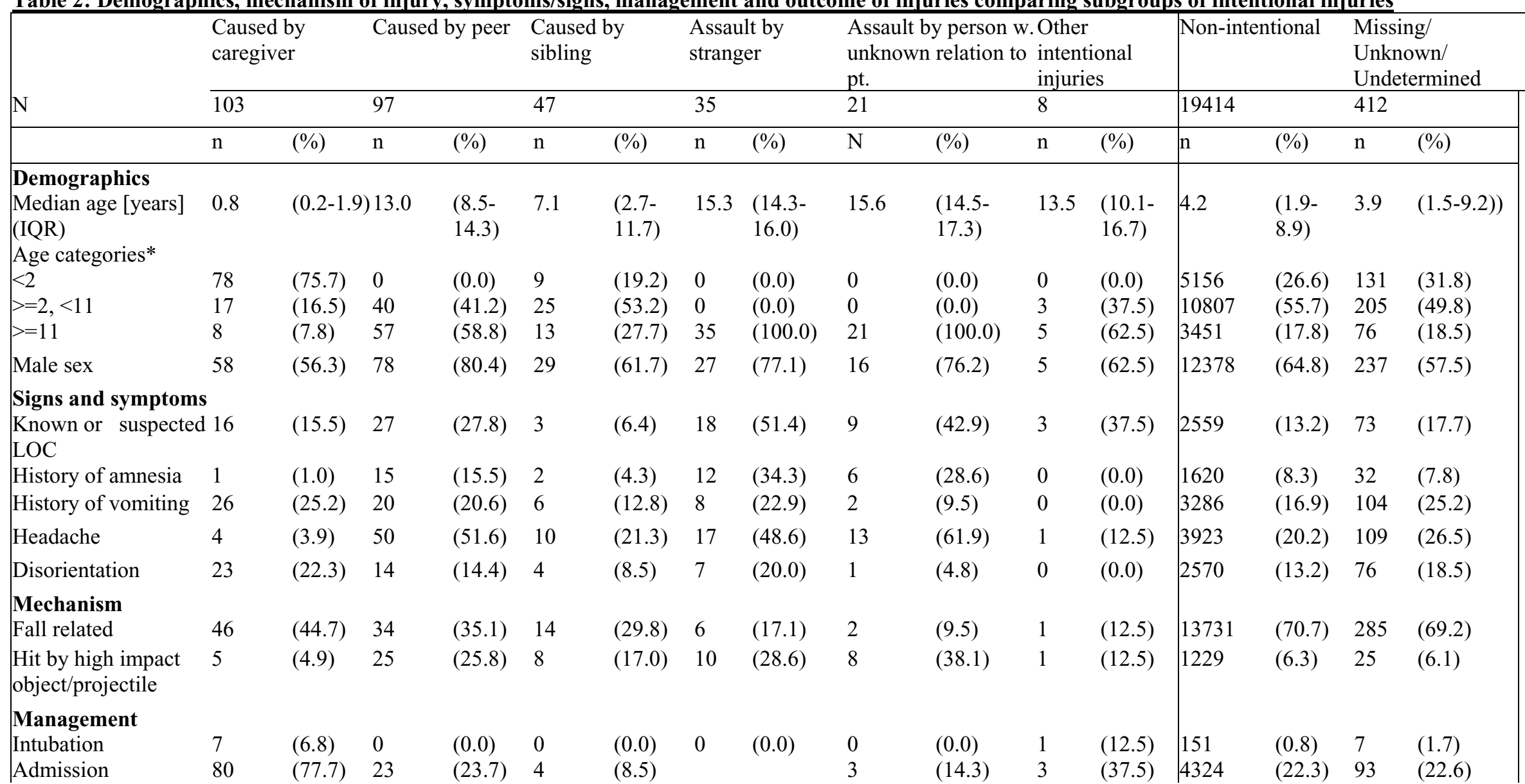

This article is protected by copyright. All rights reserved. 


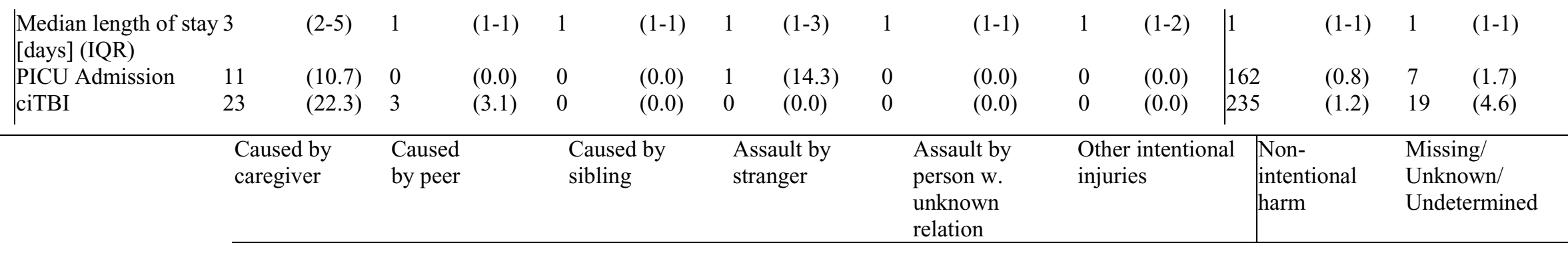

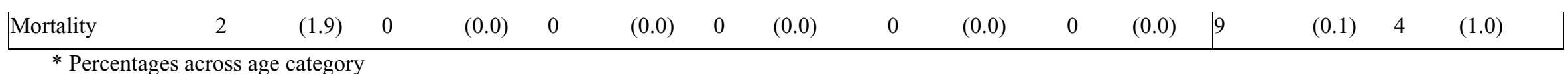


Eigure 1-Distribution of intentional iniuries.
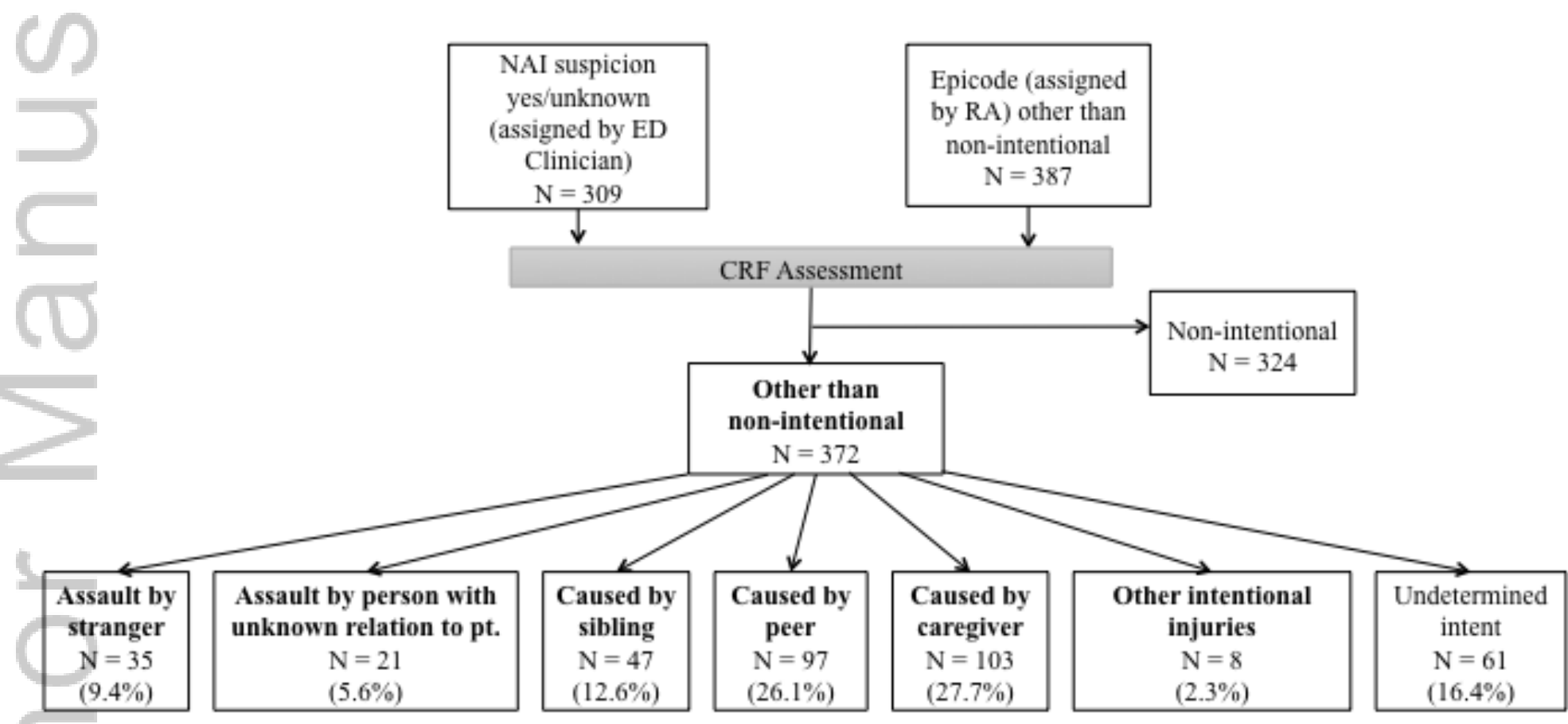

CRF - clinical report form, ED - emergency department, NAHI - non-accidental head injury, RA - research assistant

Figure 1.tiff

This article is protected by copyright. All rights reserved. 
Eigure 2: Distribution of intentional injuries by age

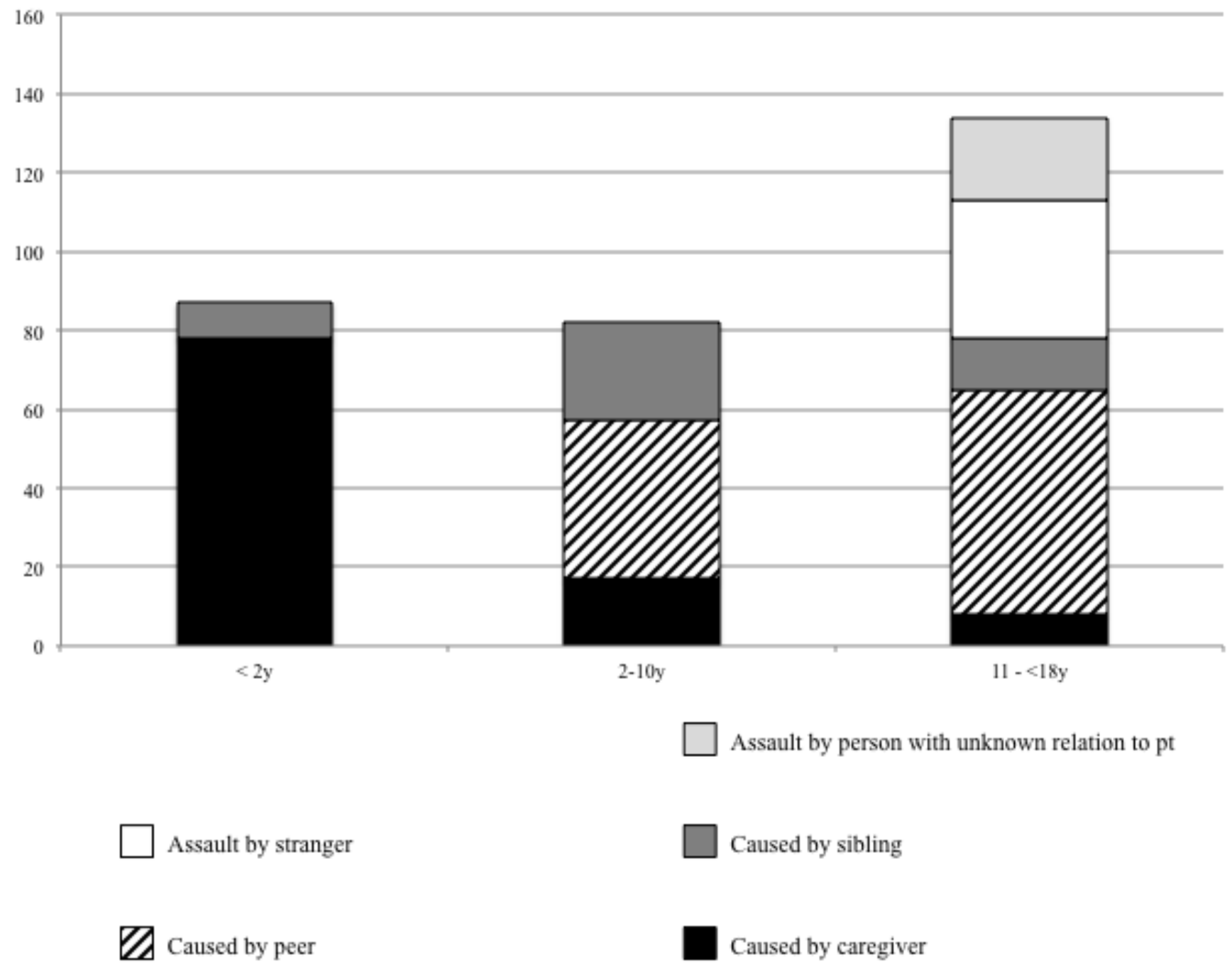

Figure 2.tiff

This article is protected by copyright. All rights reserved. 


\section{Figure 3: Distribution of intentional injuries by places of injury}

Home - Living Area

School

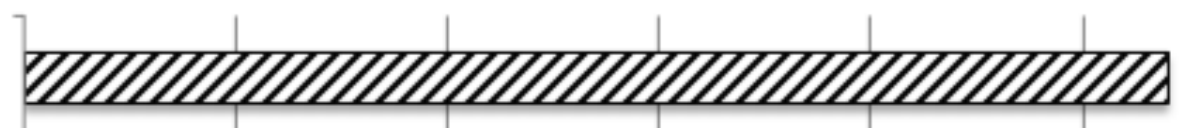

Home - Bedroom

Other Home Area

School Playground

Footpath

Other specified place

Other Residential Insititution

Day Care Centre/ Kindergarten

Other Recreational Area

Sports Area - Outdoor

Unspecified Place
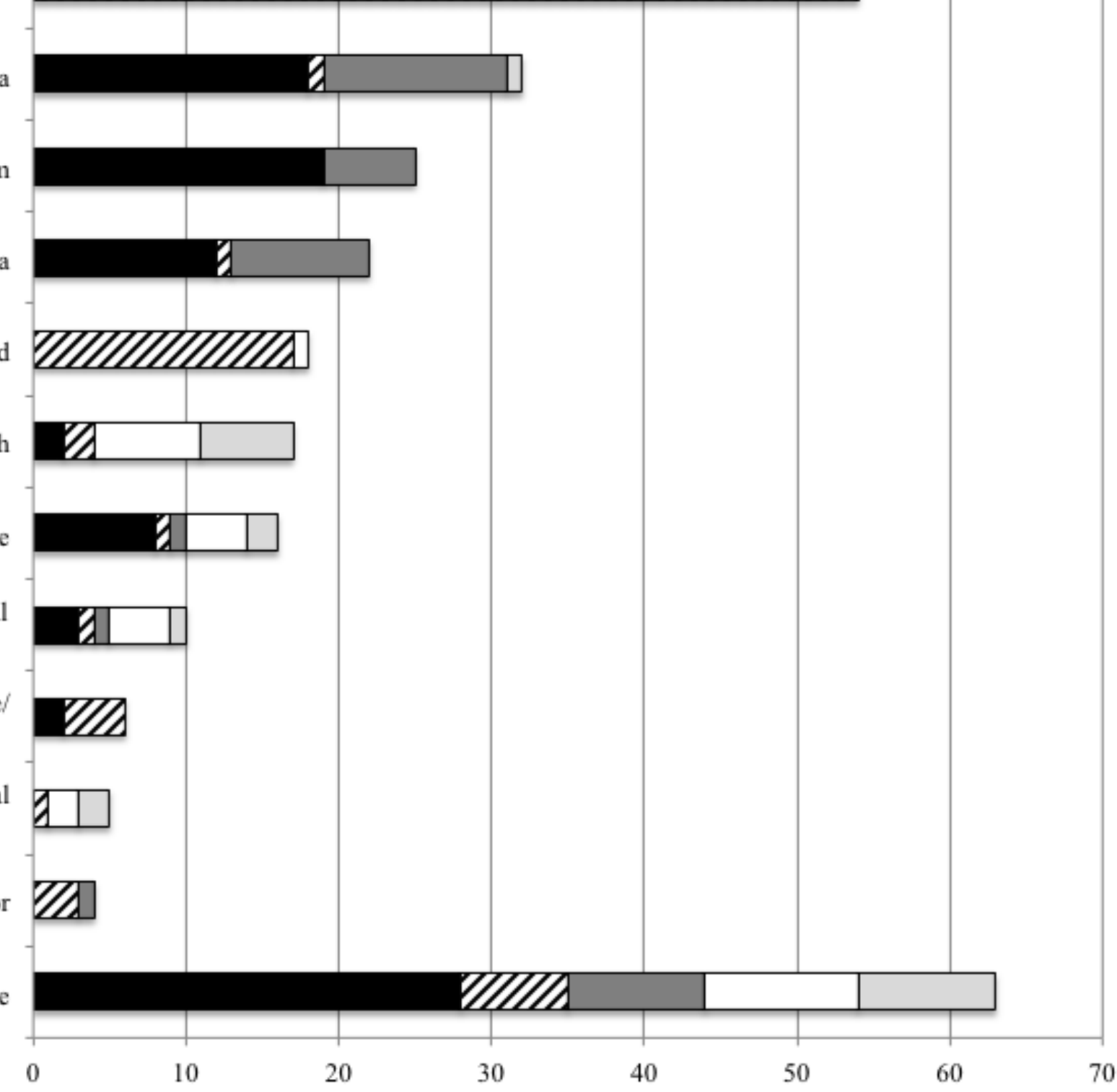

Caused by caregiver

$\square$ Caused by peer

Caused by sibling

Assault by stranger

Assault by person with unknown relation to $\mathrm{pt}$

Other codes that were used three times or less: unknown, road-sealed, railway station, home stairs, home-kitchen , home - Yard/Garden, park (2), home-bathroom (2), other trade or service area (1), restaurant/eating area (1), shops (1), shopping area (1), other public admin area (1), playground (1), car park (1), beach/ocean (1), home-laundry (1), homedriveway (1), sports area - indoor (1) 


\section{Figure 4: Percentage of CT scan and detected abnormality by injury cause}

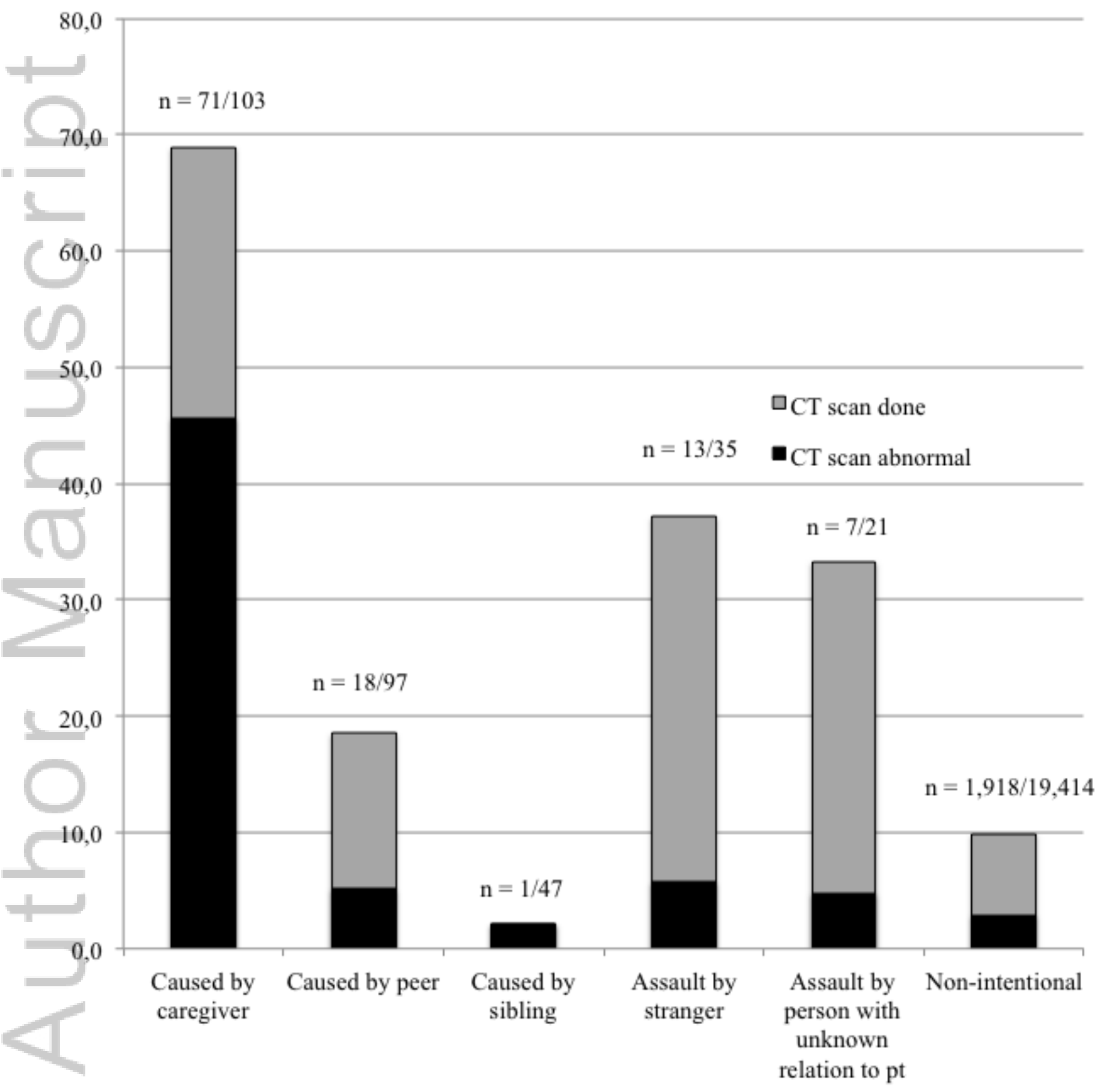

This article is protected by copyright Af.Aff rights reserved. 
Figure 5: Distribution of intentional injuries by time of injury

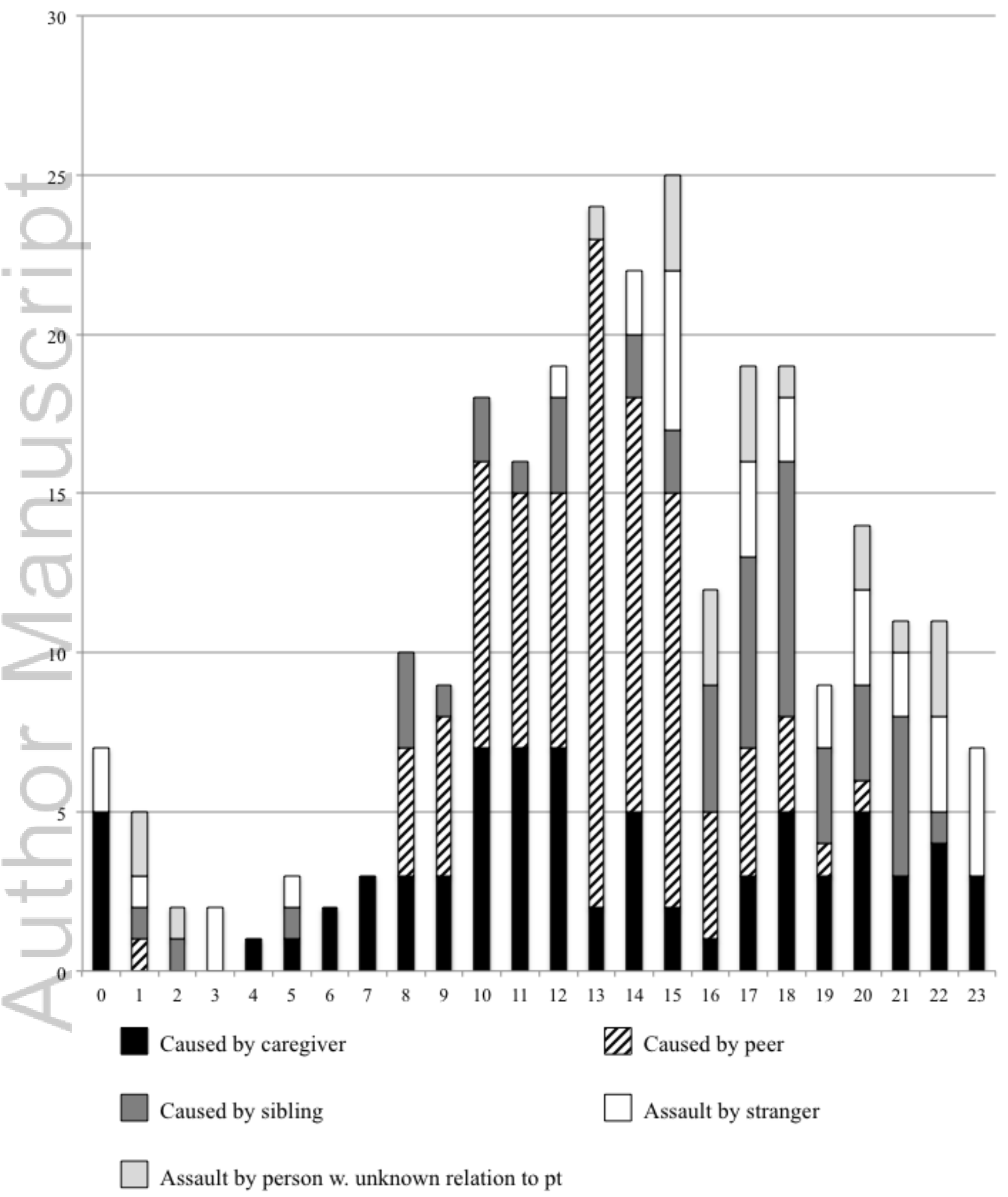

This article is protected by copyright, Aff rights reserved. 


\section{University Library}

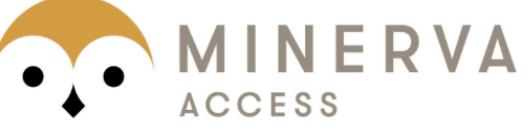

A gateway to Melbourne's research publications

Minerva Access is the Institutional Repository of The University of Melbourne

Author/s:

Babl, FE;Pfeiffer, H;Dalziel, SR;Oakley, E;Anderson, V;Borland, ML;Phillips, N;Kochar, A;Dalton, S;Cheek, JA;Gilhotra, Y;Furyk, J;Neutze, J;Lyttle, MD;Bressan, S;Donath, S; Hearps, SJC;Crowe, L

Title:

Paediatric intentional head injuries in the emergency department: A multicentre prospective cohort study

Date:

2019-08-01

Citation:

Babl, F. E., Pfeiffer, H., Dalziel, S. R., Oakley, E., Anderson, V., Borland, M. L., Phillips, N., Kochar, A., Dalton, S., Cheek, J. A., Gilhotra, Y., Furyk, J., Neutze, J., Lyttle, M. D., Bressan, S., Donath, S., Hearps, S. J. C. \& Crowe, L. (2019). Paediatric intentional head injuries in the emergency department: A multicentre prospective cohort study. EMERGENCY MEDICINE AUSTRALASIA, 31 (4), pp.546-554. https://doi.org/10.1111/1742-6723.13202.

Persistent Link:

http://hdl.handle.net/11343/283424 